Fish who Answer the Telephone: and other Studies in Experimental Biology. By Prof. Y. Frolov. Translated from the Russian by Stephen Graham. Pp. $x+168+14$ plates. (London : Kegan Paul and Co., Ltd., 1937.) 6s. net.

7 HIS chatty little volume should be welcomed by experimental biologists and will make fascinating reading for the layman who is at all interested in the experimental work now being prosecuted on animal behaviour.

The work of Pavlov is well known to all biologists -especially physiologists-and Prof. Frolov, who worked with Pavlov, has for many years pursued similar lines of investigation. Though this book (with a misleading main title, since it signifies the content of one chapter only) does not claim to give scientific detail of value to research workers, it makes interesting fireside reading for a biologist and gives him a good insight into the experimental method of Frolov and his school. Furthermore, many biologists, especially those beginning their careers, will learn much of academic interest; for example, that Amphioxus was discovered by Alexander Kovalevsky in an inlet on the Crimean shore, that the well-known Marine Biological Station at Naples was first of all suggested by the German biologist, Dohrn, and is actually the oldest of such stations, that Frolov himself was the first to claim to have demonstrated a sense of hearing in fish (though whether Prof. von Frisch would agree is an open question), and that much which has been written about instinct and behaviour in ants is the product more of imagination rather than of observation.

More mature psychologists and physiologists will be pleased to revive their memories of work on the behaviour of dogs, experiments on the behaviour of chickens even before they are hatched, and so forth.

Anyone opening the book will be unlikely to put it down until he has read it from cover to cover. Mr. Graham is to be congratulated on translating the work in a most pleasing style.

\section{Geological Excursion Guide to the Assynt District of Sutherland}

By Dr. M. Macgregor and Dr. J. Phemister. Pp. $62+4$ plates. (Edinburgh : Edinburgh Geological Society, 1937.) 28 .

7 HANKS to the Edinburgh Geological Society, 1 the visitor to the Assynt district of Sutherland is now well equipped. The authors give a carefully planned descriptive itinerary of a series of seven excursions to ground easily accessible from Inchnadamph. All the localities are capable of being visited and examined during a week's stay in the neighbourhood; shorter itineraries also are provided, indicating how to use to the best advantage periods of four, three and two days. The detailed excursion section of the guide is prefaced by a short but clear summary of the geology and structure.

The thoroughness of the authors is shown by the provision of a glossary of place-names, an index, blank pages for notes, and details regarding transport and accommodation. The details of the excursions have been carefully checked in the field, and are fully illustrated by four excellent colour-printed maps and three other sketch-maps in the text. The visitor may be confidently assured that with this guide in one pocket and the one-inch Geological Survey map of Assynt in another he will miss none of the main features of this fascinating district. $\mathrm{He}_{\Theta}$ must not forget the map, for it contains important 'vertical' and 'horizontal' sections which make it an essential complement to the guide.

Enthusiasts will find that the excursions keep them fully occupied. Non-specialists, however, may think that the petrological picnics to Loch Borrolan (of borolanite fame) and Loch Ailsh might be replaced, in part at least, by an excursion of a more leisurely character to one of the places they have already visited; for they are sure to have fallen in love with at least one particular spot or view in such wonderful country.

T. R.

\section{Technical Electricity:}

Principles and Practice. By J. E. Phillips and Dr. R. W. B. Stephens. Pp. vii +288 . (London: The Technical Press, Ltd., 1937.) 7s. $6 d$.

7 HE great difficulty with students of electrical 1 engineering in technical colleges is that they have very little training in physics, and several wellmeaning text-books have been produced recently which try to instil fundamental magnetic and electric principles in the shortest possible time, and without making the student tired with difficult discussions about electro-magnetic units and the reason why one way of deducing our definitions of the intensities of fields and so on is preferable to another. There is always the outstanding difficulty why we use unit magnetic poles for definitions when no such pole exists; it is a difficulty which each teacher must solve for himself, before trying to train the immature mind to think in similar terms. The present authors succeed as well as some others, but perhaps tend to err on the more practical side. This is a good fault, however, since the type of student in view is best appealed to through his practical experience-sometimes more up to date than that of his teacher.

\section{Modern Management}

L. E. C. H.

By Prof. J. E. Walters. Pp. xiv +337. (New York : John Wiley and Sons, Inc.; London : Chapman and H.all, Ltd., 1937.) 158. net.

7 HIS book gives a reasonably comprehensive account of the methods of modern management and of the practical applications of the scientific method to various phases of management. It is emphatically not a book for the general reader; but if it contains rather too much detail for him, those who are concerned with particular problems of management may perhaps regret that its account of the Gantt Chart, the Bedaux system and similar matters is rather too condensed. On the whole, however, it is a well-balanced work, although the section on organization and its principles might with advantage have been expanded. Selected biblio. graphies are appended to each chapter, and these are reasonably representative, although relating in the main only to American publications. 